\title{
Bypass of Impending Intestinal Obstruction
}

National Cancer Institute

\section{Source}

National Cancer Institute. Bypass of Impending Intestinal Obstruction. NCI Thesaurus.

Code C135733.

Surgical bypass of an impending intestinal obstruction. 